Int. J. Dev. Biol. 57: 55-60 (2013)

doi: $10.1387 / \mathrm{ijdb} .120117 \mathrm{yk}$

\title{
Microtubule disassembly prevents palatal fusion and alters regulation of the E-cadherin/catenin complex
}

\author{
YUKIKO KITASE and CHARLES F. SHULER* \\ Department of Oral Biological and Medical Sciences, Faculty of Dentistry, University of British Columbia, Vancouver BC, Canada
}

\begin{abstract}
During palatal fusion, the midline epithelial seam (MES) degrades to achieve mesenchymal confluence. Epithelial mesenchymal transition (EMT) is one mechanism which is active in MES degradation. TGF- $\beta$ induces EMT in medial edge epithelium (MEE) by down-regulation of an epithelial marker, E-cadherin. Microtubule disassembly impaired palatal fusion leading to a multilayered MES in the mid-region. In this study, we investigated the effect of microtubule disruption on the regulation of the E-cadherin/catenin adhesion complex. Nocodazole (NDZ) enhanced the accumulation of the adhesion complex at cell-cell contacts in MEE, while loss of the adhesion complex was observed in the control. NDZ caused aberrant regulation of the E-cadherin transcriptional repressors (Snail and Zeb) and the activator (c-MYC) through inhibition of the TGF-B/SMAD2 signaling pathway, which led to a failure in EMT.These results suggest that the microtubule cytoskeleton plays an important role in mediating TGF- $\beta /$ SMAD2 signals to control $E$-cadherin gene expression in MEE during palatal fusion.
\end{abstract}

KEY WORDS: microtubule, palatal fusion, EMT, E-cadherin/catenin adhesion complex, TGF- $\beta / S M A D 2$

\section{Introduction}

Formation of the secondary palate is a complex and critical event involving tightly regulated palatal shelf outgrowth, reorientation, adhesion and fusion. Disturbance at any step during palatal development may result in cleft palate, a common birth defect in humans (Ferguson, 1988). The opposing palatal shelves approach each other in the midline after re-orientation from a vertical position. The medial edge epithelia (MEE) adhere and form, via intercalation, a single layer called the medial epithelial seam (MES). Degradation of the MES proceeds to achieve the confluence of palatal mesenchyme and complete the process of palatal fusion (Ferguson, 1988).

Epithelial mesenchymal transition (EMT) plays a crucial role in MES degradation (Greene and Pisano, 2010, Griffith and Hay, 1992, Jalali et al., 2012, Jin and Ding, 2006, Shuler et al., 1992, Yu W, 2009). It is characterized by loss of epithelial cell morphology and acquisition of mesenchymal properties. To maintain epithelial integrity a calcium-dependent homophilic adhesion molecule, E-cadherin, exerts adhesive function by binding to the cytoplasmic $\alpha$ - and $\beta$-catenin proteins, which serve to link the cadherin to the actin cytoskeleton (van Roy and Berx, 2008). $\mathrm{E}$-cadherin transcription is tightly regulated through the promoter that contains a CAAT box, a GC rich region and an E-box. The transcription factor $\mathrm{c}-\mathrm{MYC}$ transactivates E-cadherin through its direct interaction with the E-box or as a co-activator of AP-2 transcription factor, which interacts with the GC-rich region (Batsche et al., 1998, Liu et al., 2009). TGF- $\beta$ negatively regulates c-MYC (Pietenpol et al., 1990). Transcriptional repression of E-cadherin is a key molecular event in EMT (Peinado et al., 2004). Down regulation of $\mathrm{E}$-cadherin by transcriptional repressors such as the zinc finger factor Snail (Snai1 and Snai2), two-handed zinc finger factor Zeb (Zeb1 and Zeb2) is an essential mechanism by which TGF- $\beta$ elicits EMT (Dave et al., 2011, Jalali et al., 2012, Pirozzi et al., 2011, Shirakihara et al., 2007). The signaling pathway is well known to induce EMT in MEE during palatal fusion (Kaartinen et al., 1997, Sun et al., 1998).

We have shown that microtubule disruption by nocodazole (NDZ), a widely used microtubule de-stabilizing agent, inhibited palatal fusion accompanied with the development of a multilayered MES in the mid-palatal region (Kitase and Shuler, 2012). In this study, we investigated the underlying mechanism by which NDZ exposure resulted in the accumulation of cell-cell adhesion proteins at intercellular junctions in MEE. These findings provided evidence that microtubule disruption impaired the mechanism

Abbreviations used in this paper: EMT, epithelial mesenchymal transition; MES, midline epithelial seam; MEE, medial edge epithelium; NDZ, nocodazole.

\footnotetext{
*Address correspondence to: Charles F. Shuler. 2194 Health Sciences Mall, Vancouver, BC V6T 1Z3, Canada. Tel: +1-604-822-5773. Fax: +1-604-822-4532. e-mail: cshuler@dentistry.ubc.ca
} 
for EMT. In this study we investigated the role of microtubules on the transcriptional regulation of the adhesion proteins. Our results provided evidence that the microtubule cytoskeleton plays a crucial role in EMT through regulation of TGF- $\beta / S M A D 2$ signaling during palatal fusion and inhibiting the repression of E-cadherin.

\section{Results}

\section{Microtubule disassembly inhibits palatal fusion leading to a multi-layered MES formation in the mid-region}

We observed induction of multi-layered MES formation in the palate mid-region when in vitro palate shelf organ cultures were treated with a microtubule-disrupting agent, NDZ. The MES disappeared to achieve complete mesenchymal confluence in control organ cultures while NDZ treated cultures had a persistence of a multilayered MES (Fig.1).

\section{Microtubule disassembly results in the accumulation of E- cadherin/catenin adhesion complexes at cell-cell junctions in MEE}

We examined whether MEE treated with NDZ maintained intact E-cadherin/catenin cell adhesion complexes at the intercellular junction. In control organ cultures, down-regulation of E-cadherin and the associated catenins such as $p 120$ catenin, $\beta$-catenin and $\alpha$ catenin occurred during palatal fusion. The intensity of 120 catenin and $\alpha$-catenin signals is approximately 3 - and 10 -fold weaker than for E-cadherin in all cultures (Fig. 2Aa,b). The adhesion molecule proteins became concentrated at cell-cell junctions in MEE treated

\section{Control}
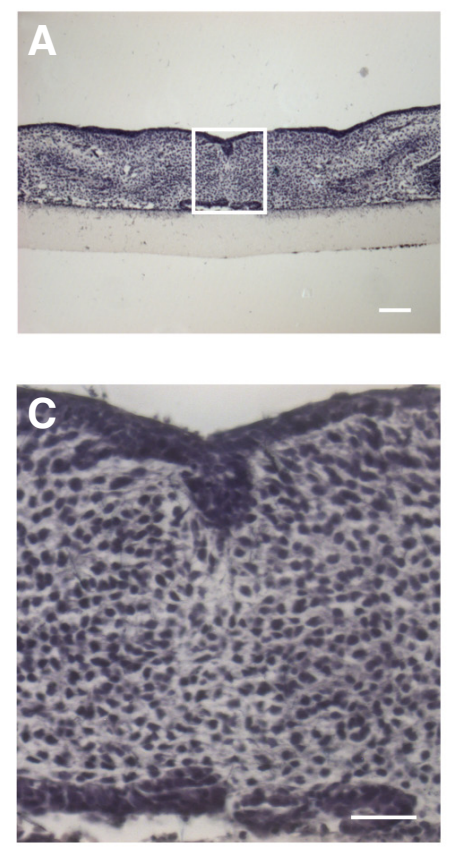

NDZ
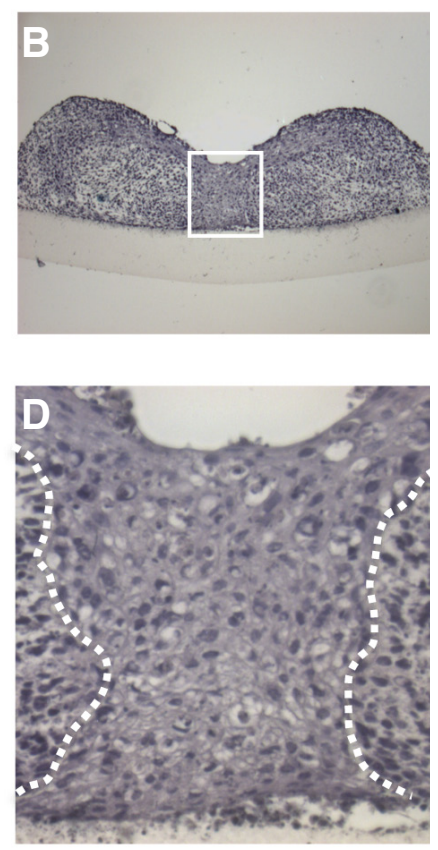

Fig. 1. Microtubule disassembly inhibits palatal fusion resulting in multi-layered MES formation in the mid-region. Hematoxylin staining. Representative sections shown for control $(\mathbf{A}, \mathbf{C})$ and $30 \mu \mathrm{MNDZ}(\mathbf{B}, \mathbf{D})$ were taken from 72 h organ cultured palatal tissue. (C,D) High magnification images from the rectangular area shown in $(\mathbf{A}, \mathbf{B})$ respectively. Scale bar, $100 \mu \mathrm{m}$. with NDZ over long-term culture periods (Fig. 2Bc-e). Palatal organ cultures from TGF- $\beta 3$ null mice exhibited failure of degradation of E-cadherin/catenin adhesion complex in control and developed multi-layered MES and accumulation of the adhesion complex under long-term treatment of NDZ (Fig. 2Ac and Bd).

\section{Microtubule disassembly alters the expression of E-cadherin/ catenin adhesion molecule genes}

We investigated the effect of NDZ on the expression of adhesion molecule genes by quantitative real-time PCR to understand the underlying mechanism by which the accumulation of the adhesion molecule proteins occurred at cell-cell junctions (Fig. 3). E-cadherin mRNA was increased more than 2-, 4- and 5-fold at 24, 48 and $72 \mathrm{~h}$ respectively. p120 catenin mRNA was also increased more than 2 -fold at 72 hours while $\beta$-catenin mRNA was inhibited approximately 2 -fold at all time points measured. There were no significant changes in $\alpha$-catenin mRNA expression.

\section{Microtubule disassembly inhibits TGF- $\beta / S M A D 2$ signaling re- sulting in down-regulation of EMT-related transcription factors}

Both E-cadherin and $\beta$-catenin are downstream target genes regulated by TGF- $\beta$ signaling, which is also essential to mediate EMT signals (Peinado et al., 2004, Pirozzi et al., 2011). Failure in transcriptional down-regulation of E-cadherin and up-regulation in $\beta$-catenin following microtubule disassembly led us to examine whether NDZ effects TGF- $\beta$ signaling. TGF- $\beta$ signaling during palatal fusion was evaluated by detecting phospho-SMAD2. Immunofluorescence analysis revealed strong phospho-SMAD2 signals in most MEE after adhesion of the opposing palatal shelves, while few signals were detected in MEE before adhesion in control (Fig. $4 \mathrm{Aa}, \mathrm{b})$. By contrast, NDZ blocked activation of TGF- $\beta$ signaling. The NDZ exposed MEE have almost no phospho-SMAD2 signals at all the time points examined (Fig. 4Ac-e). We performed quantitative real-time PCR to examine the expression level of EMT-related transcription factors regulated by TGF- $\beta$. All of the transcription factors exhibited an approximately 2 -fold decrease at all the time points measured (Fig. 4B).

\section{Microtubule disassembly failed to down regulate c-MYC associated with ID2 induction}

The balance between negative and positive regulatory pathways controlling transcription affects total E-cadherin mRNA level. To explore the effect of NDZ on the inductive regulatory pathway, we performed immunofluorescence analysis to investigate the expression level of $\mathrm{c}-\mathrm{MYC}$. The strong signals were observed in MEE before adhesion in control and its expression was inhibited after adhesion, which is inversely correlated with the expression level of phospho-SMAD2 during palatal fusion (Fig. 5Aa,b). By contrast, NDZ maintained c-MYC expression in MEE even at $48 \mathrm{~h}$ (Fig. 5Acd). c-MYC is well known to induce a bHLH transcriptional factor ID2 in association with the MAX transcription factor (Lasorella et al., 2000). Failure of c-MYC down-regulation by TGF- $\beta / S M A D 2$ due to microtubule disassembly may secondarily lead to ID2 induction. We therefore examined the expression level of the protein, which also acts as a negative regulator of TGF- $\beta$-induced EMT through negatively modulating the transcription of Zeb (Shirakihara et al., 2007). In control, most MEE showed strong ID2 signals before adhesion, but weak signals were detected in some MEE after adhesion, which indicates down-regulation by TGF- $\beta$ during palatal 


\section{A}
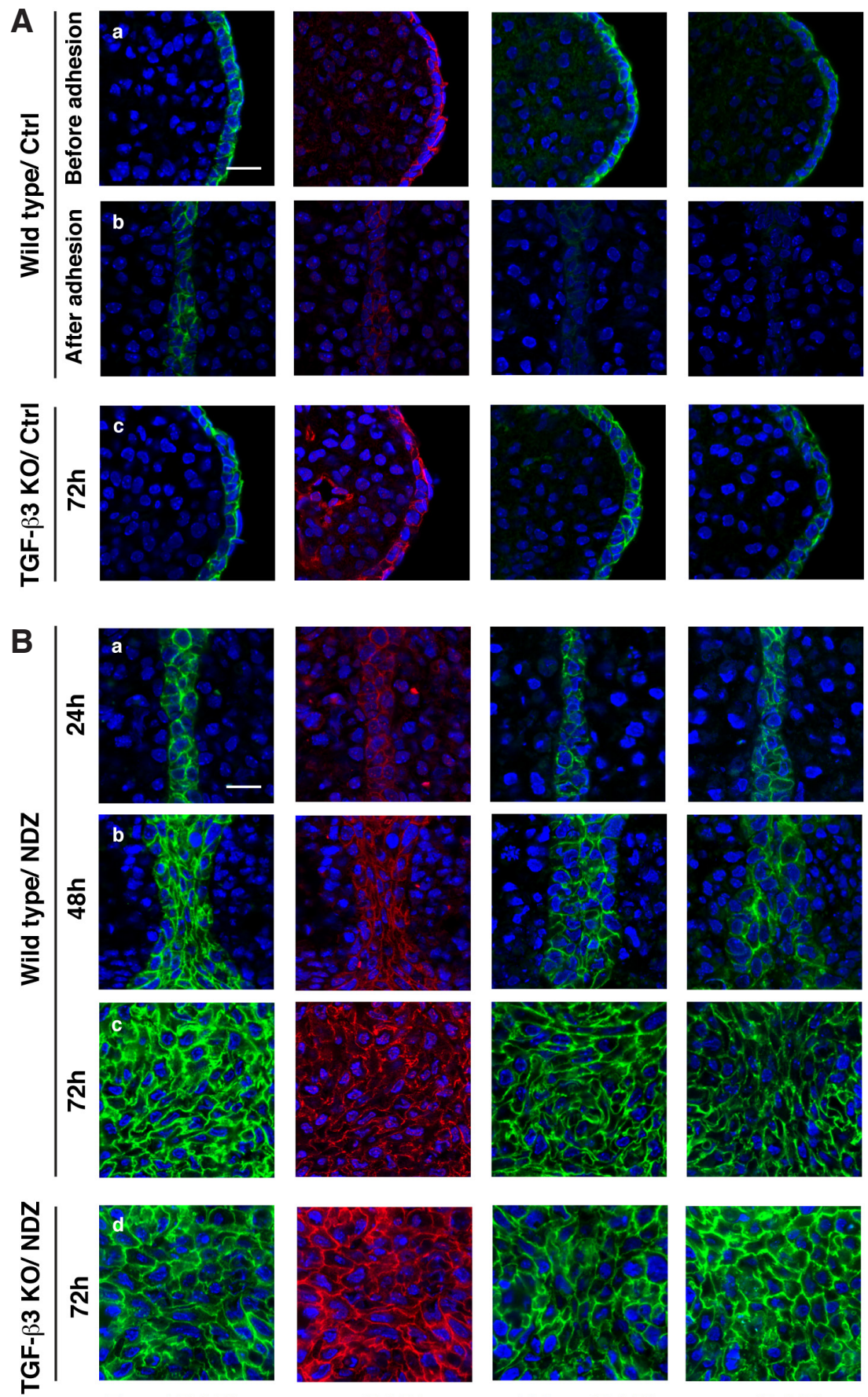

E-cad/DAPI
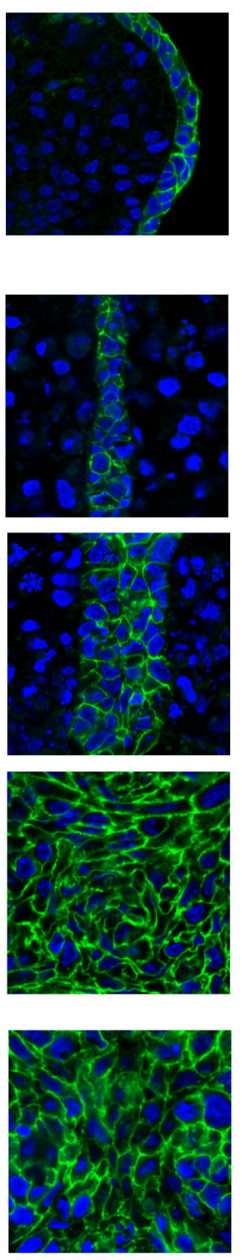

p120cat/DAPI
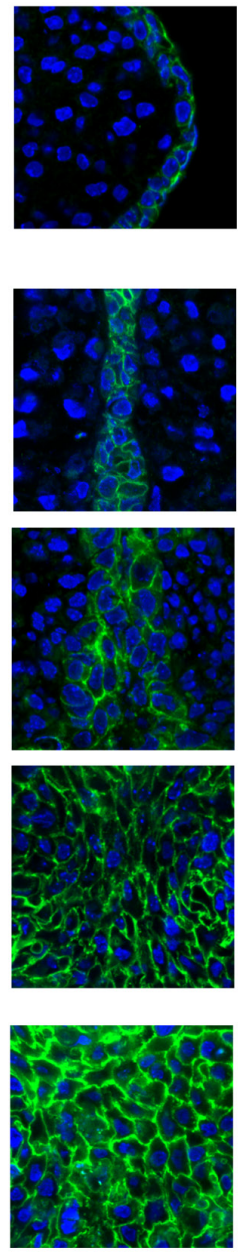

$\alpha$-cat/DAPI
Fig. 2 (left). Microtubule disassembly results in the accumulation of E-cadherin/catenin adhesion complexes at cell-cell junctions in MEE. Organ cultured were performed with (B) or without $30 \mu \mathrm{M} \mathrm{NDZ}$ (A). Fluorescent images of E-cadherin (green), $\beta$-catenin (red), p120 catenin (green), $\alpha$-catenin (green) and DAPI (blue). Representative sections shown for wild type/ control (a: before adhesion, b: after adhesion), TGF- $\beta 3 K O /$ control (c: $72 \mathrm{~h})$, wild type/ $30 \mu \mathrm{M}$ NDZ (c: 24 h, d: 48 h, e: 72 h) and TGF- $\beta 3 K O / 30 \mu \mathrm{M} \mathrm{NDZ}$ (d: 72h) were taken from palatal tissue. Scale bar, $20 \mu \mathrm{m}$.
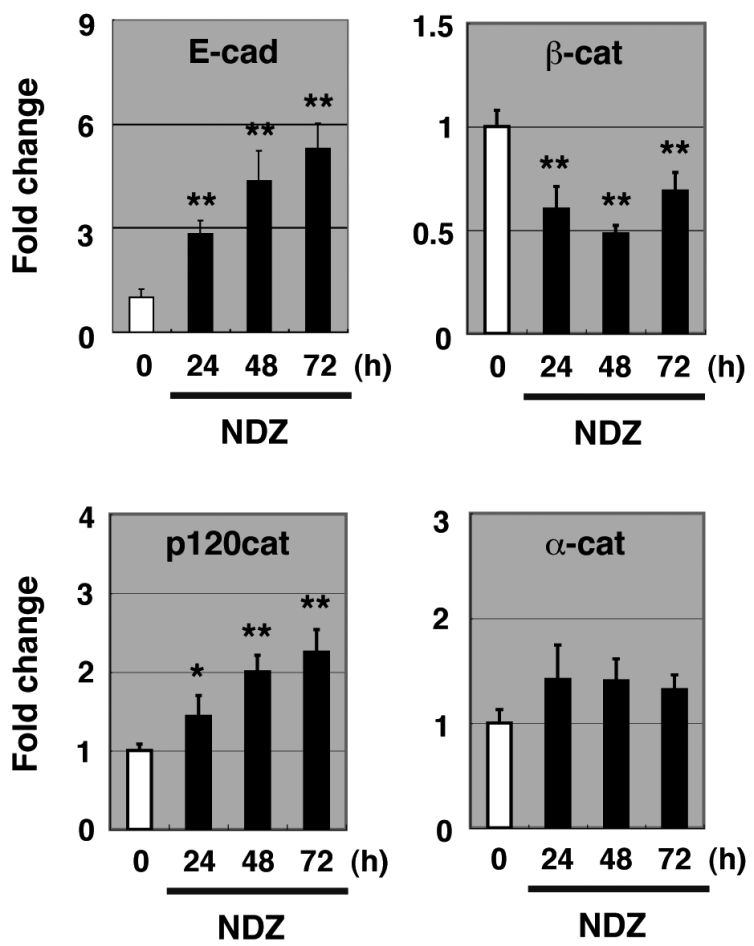

Fig. 3 (above). Microtubule disassembly alters expression of E-cadherin/catenin adhesion molecule genes. Quantitative real-time PCR analysis of gene expression encoding E-cadherin, $\beta$-catenin, p120 catenin and $\alpha$-catenin in palatal tissue treated with $30 \mu \mathrm{M} N D Z$ for the indicated period. GAPDH was used as reference for normalization. ${ }^{*} \mathrm{P}<0.05$ and ${ }^{*} \mathrm{P}<0.01$ compared to control. fusion (Fig. 5A). NDZ increased expression of ID2 with maximum induction at $72 \mathrm{~h}$ (Fig. 5B).

\section{Discussion}

E-cadherin and its associated catenin adhesion complex are down-regulated in MEE destined to undergo EMT to accomplish mesenchymal confluence (Schmid, 2002). E-cadherin plays crucial roles in maintaining epithelial cell polarity and integrity. We observed earlier onset of degradation of $p 120$ catenin and $\alpha$-catenin than of E-cadherin when palatal fusion was examined in control samples.
The stability of E-cadherin at cell junctions is dependent on p120 catenin and $\alpha$-catenin. p120 catenin stabilizes the adhesion complex at cell-cell junctions via masking the di-leucine motif and tyrosine residues of the juxtamembrane domain of E-cadherin to prevent the clathrin-mediated endocytosis and Hakai-dependent ubiquitination of E-cadherin (Ishiyama et al., 2010). Knockdown of p120 catenin increases the level of E-cadherin endocytosis (Miyashita and Ozawa, 2007). $\alpha$-catenin links E-cadherin through $\beta$-catenin to the actin cytoskeleton to provide stable cell adhesion (Rimm et al., 1995). Loss of $\alpha$-catenin reduced E-cadherin cellcell adhesion and the restoration of $\alpha$-catenin rescued $E$-cadherin 


\section{A Control}
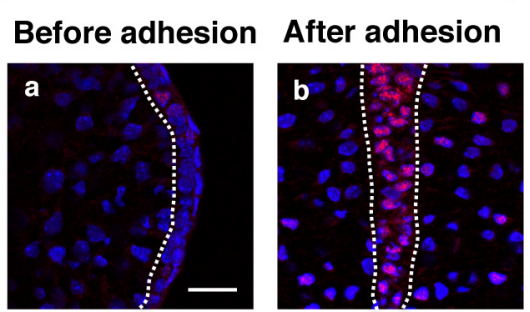

p-SMAD2/DAPI

\section{NDZ}
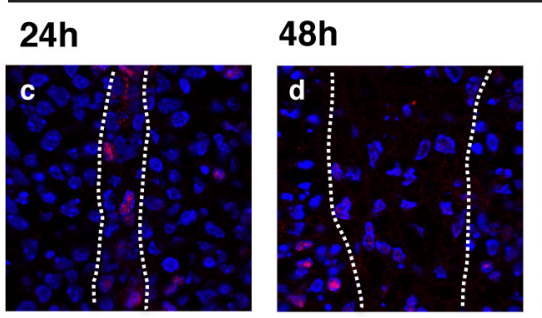

$72 \mathrm{~h}$

B
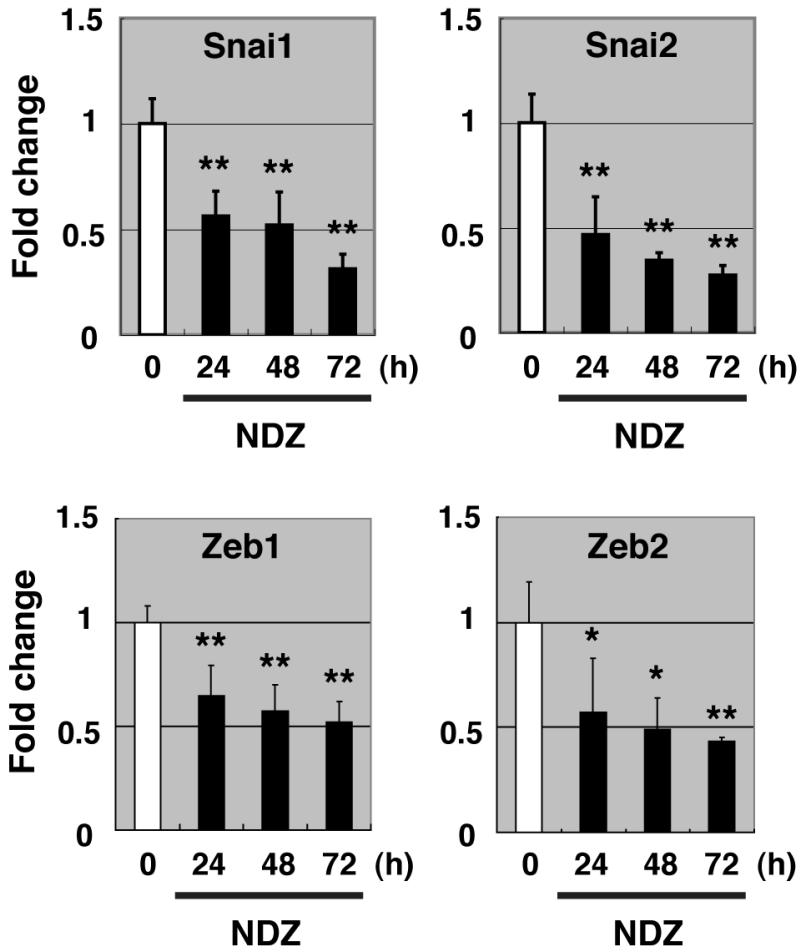

Fig. 4. Microtubule disassembly inhibits TGF- $\beta$ /SMAD2 signaling resulting in the down-regulation of EMT-related transcription factors. (A) Fluorescent images of phospho-SMAD2 (red) and DAPI (blue). Representative sections shown for control (a: before adhesion, $b$ : after adhesion) and $30 \mu \mathrm{M} \mathrm{NDZ} \mathrm{(c:} 24 \mathrm{~h}, \mathrm{~d}: 48 \mathrm{~h}, \mathrm{e:} 72 \mathrm{~h}$ ) were taken from palatal tissue. Scale bar, $20 \mu \mathrm{m}$. (B) Quantitative real-time PCR analysis of gene expression encoding Snai1, Snai2, Zeb1 and Zeb2 in palatal tissue treated with $30 \mu \mathrm{M} N D Z$ for the indicated period. GAPDH was used as reference for normalization. ${ }^{*} \mathrm{P}<0.05$ and ${ }^{*}{ }^{*} \mathrm{P}<0.01$ compared to control.

cell-cell adhesion (Inge et al., 2008, Shimoyama et al., 1992). The antecedent degradation of both proteins indicates the acceleration of E-cadherin endocytosis and loss of stability of the adhesion complexes in control. In contrast, prolonged treatment with NDZ

\section{A}
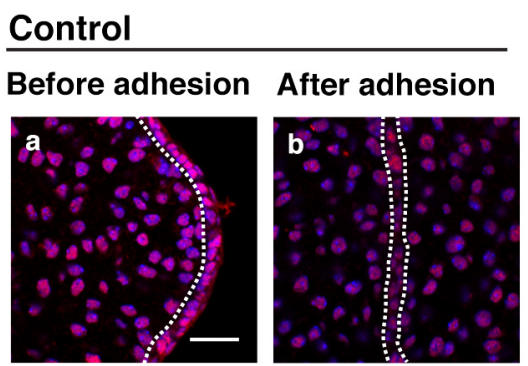

c-MYC/DAPI

NDZ
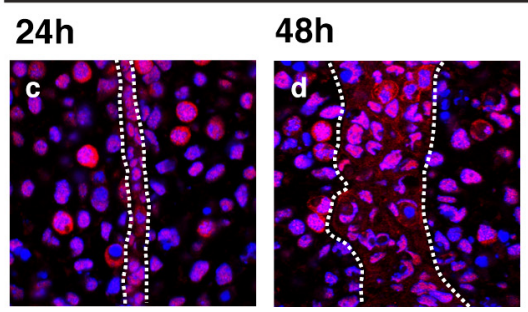

$72 \mathrm{~h}$

B

\section{Control}
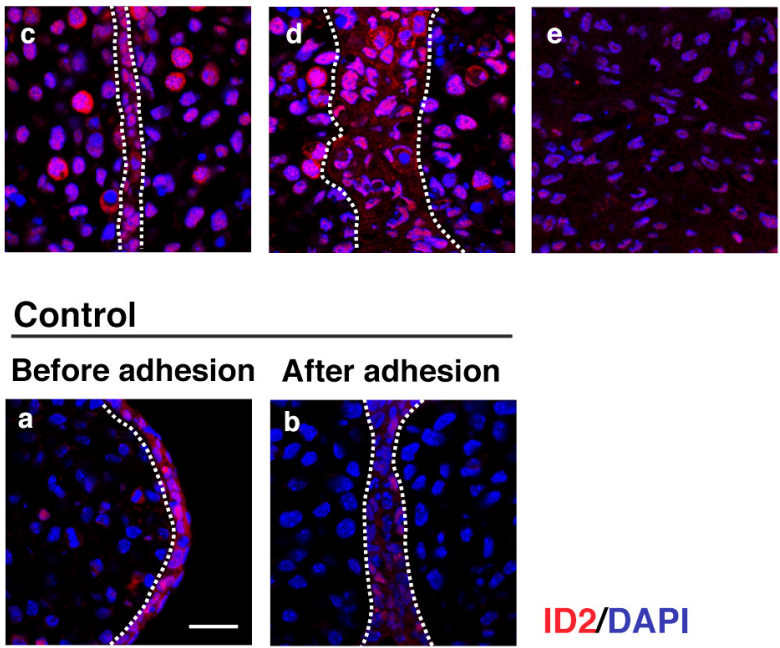

\section{NDZ}

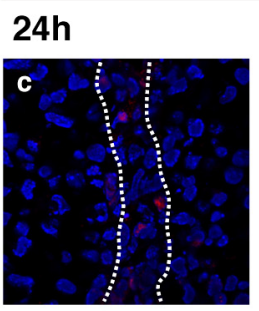

$48 \mathrm{~h}$

$72 \mathrm{~h}$
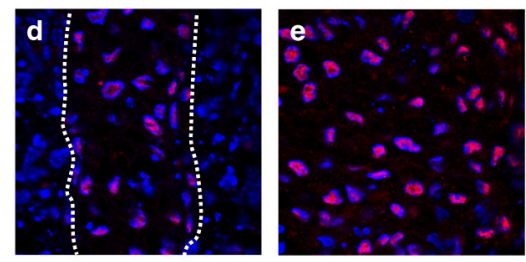

Fig. 5. Microtubule disassembly inhibited down-regulation of c-MYC associated with ID2 induction. (A) Fluorescent images of c-MYC (red) and DAPI (blue). Representative sections shown for control (a: before

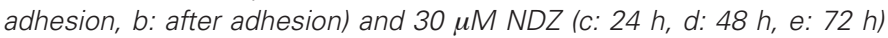
were taken from palatal tissue. (B) Fluorescent images of ID2 (red) and DAPI (blue). Representative sections shown for control (a: before adhesion, b: after adhesion) and $30 \mu \mathrm{M} \mathrm{NDZ}$ (c: $24 \mathrm{~h}, d: 48 \mathrm{~h}, \mathrm{e:} 72 \mathrm{~h})$ were taken from palatal tissue. Scale bar, $20 \mu \mathrm{m}$.

induced aberrant accumulation of the adhesion molecule proteins at cell-cell junctions in the MEE over the course of time, which was associated with the altered gene expression. Up-regulation of p120 catenin and E-cadherin transcription by NDZ may provide the means to increase the stability of the adhesion complex at intercellular junctions in the MEE.

The microtubule cytoskeleton plays a critical role in intracellular vesicle transport. Disassembly of microtubules by NDZ has been shown to influence endocytosed and endocytic vesicle transports to various endosomal compartments (Hamm-Alvarez and Sheetz, 
A

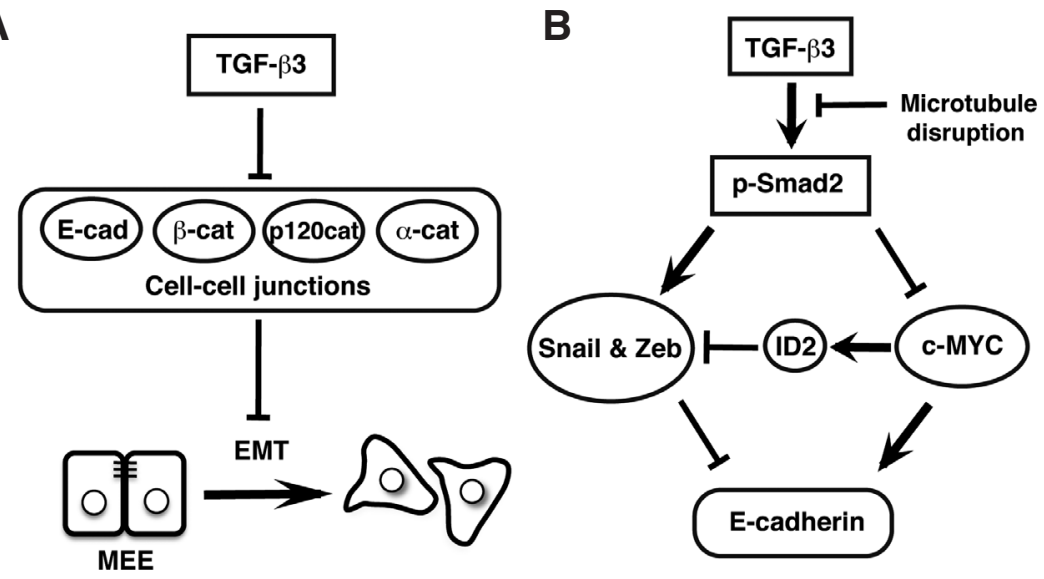

Fig. 6. A proposed model for the underlying mechanism of altered regulation of E-cadherin/catenin adhesion complex by long-term treatment of NDZ. (A) Cell-cell adhesion complex, E-cadherin and catenins in MEE are to degrade leading to EMT during palatal fusion. TGF- $\beta$ negatively regulates the E-cadherin/catenin adhesion complex, which maintains epithelial phenotype, at transcriptional and post-transcriptional levels. (B) The role of microtubule cytoskeleton in the regulation of E-cadherin expression in MEE. Microtubule disruption by NDZ prevents phosphorylation of Smad2 induced by TGF- $\beta$ during palatal fusion and thereby causes aberrant regulation of E-cadherin transcriptional repressors; Snail and Zeb and an activator; c-MYC leading to accumulation of E-cadherin at cell-cell junction, which resulted in accumulation of E-cadherin at intercellular junctions and failure of EMT.

1998, Jin and Snider, 1993). The TGF- $3 /$ SMAD2 signaling pathway is involved in the negative regulation of E-cadherin transcription during the EMT process (Dave et al., 2011, Pirozzi et al., 2011, Shirakihara et al., 2007). TGF- $\beta$ signaling is dependent on the membrane traffic of the internalized TGF- $\beta$ /receptor complex to the early endosome where receptor-mediated SMAD phosphorylation occurs. Subsequently phosphorylated SMAD reaches the nucleus to facilitate transcription of the target genes (Chen, 2009). The SMAD nuclear translocation has been reported to be dependent on microtubules and the associated motor protein, dynein (Jin et al., 2009). Impairment in trafficking of the TGF- $\beta$ /receptor complex vesicles and activated SMAD by microtubule disassembly may interfere with the MEE disappearance process due to the improper regulation of E-cadherin transcription. We therefore investigated the effect of NDZon the TGF- $\beta$ /SMAD2 signaling pathway. Immunofluorescence analysis successfully clarified that prolonged NDZ treatment blocked activation of SMAD2, which suggests the microtubule disassembly prevents the trafficking of the endocytosed TGF- $\beta$ /receptor complex vesicles to the early endosomes resulting in a failure to mediate the signals in the MEE during palatal fusion. Quantitative real-time PCR also revealed that NDZ inhibited the transcription factors, Snail and Zeb in the MEE. TGF- $\beta / S M A D$ promotes EMT via induction of transcriptional repressors of E-cadherin including Snail and Zeb (Dave et al., 2011, Jalali et al., 2012, Pirozzi et al., 2011, Shirakihara et al., 2007). These findings indicated that microtubule disruption in the MEE led to a failure to down-regulate E-cadherin transcription via inhibition of the transcriptional repressors secondary to blockage of signaling from the TGF- $\beta /$ SMAD2 pathway. Results obtained from TGF- $\beta 3$ null palatal organ cultures supports that the fate of the adhesion complex is dependent on the TGF- $\beta$ pathway. NDZ however actively up-regulated $\mathrm{E}$-cadherin $\mathrm{mRNA}$ expression rather than simply maintaining the level of expression as a consequence of the failure to down-regulate E-cadherin. Gene expression is tightly regulated positively and negatively by the transcription factors. We therefore speculated that microtubule disruption affects the positive regulatory pathways that result in the induction of E-cadherin mRNA. c-MYC is one of the down-stream transcription factors regulated by TGF- $\beta$ and reported to be an E-cadherin transcriptional activator (Batsche et al., 1998, Liu et al., 2009, Pietenpol et al., 1990). We have shown that strong c-MYC signals were maintained even at $48 \mathrm{~h}$ in the MEE treated with NDZ, which was associated with its down-stream target ID2 induction. It suggests that the positive regulatory signals of c-MYC may control E-cadherin mRNA expression actively and that ID2 induced by c-MYC may affect the E-cadherin negative regulatory pathway via modulation of Zeb expression.

This study investigated the underlying mechanism by which microtubule disruption induced the aberrant accumulation of E-cadherin/catenin adhesion complexes at intercellular junctions in MEE. We evaluated the effect of NDZ on the transcriptional regulation of E-cadherin controlled by TGF- $\beta / S M A D 2$. Our results provided evidence that microtubule disruption caused aberrant expression of both negative (Snail and Zeb) and positive (c-MYC) E-cadherin transcriptional regulators by blocking the TGF- $\beta /$ SMAD2 signaling pathway, which resulted in a failure in EMT. The working molecular model we have developed is depicted in Fig. 6 . The microtubule cytoskeleton plays an important role to mediate TGF- $\beta / S M A D 2$ signals to control E-cadherin expression in MEE during palatal fusion. However, we can not exclude the possibility that long-term treatment of NDZ causes the accumulation of E-cadherin/catenin complex independently of TGF- $\beta / S M A D 2$ signaling pathway since this experimental system does not allow us to conduct rescue experiments, which are dependent on intact microtubule cytoskeleton to activate the signaling pathway, and to provide direct evidence of involvement of TGF- $\beta$ signaling pathway.

\section{Materials and Methods}

\section{Palate organ culture}

All animal procedures were performed in compliance with the regulations and guidelines of the Animal Care Committee of The University of British Columbia. Timed-pregnant C57BL6 mice were used in these studies. Palatal shelves were dissected from E13.0 mouse embryos under sterile conditions and placed in pairs on Millipore filters with their medial edges in contact. The palatal shelves were cultured in BGJb medium at $37^{\circ} \mathrm{C}$ in $5 \%$ $\mathrm{CO}_{2}$ for up to $\mathrm{E} 13.0+72 \mathrm{~h}$. Experimental groups were treated with $30 \mu \mathrm{M}$ NDZ, whereas littermate control groups were treated only with the DMSO solvent. The culture media was changed every $24 \mathrm{~h}$.

\section{Histology}

Cultured palatal shelves were collected after $72 \mathrm{~h}$ and fixed in $4 \%$ paraformaldehyde/phosphate buffered saline (PFA/PBS). After rinsing with PBS, the tissues were processed for paraffin embedding. After hematoxylin staining, light microscopic images were captured using a Zeiss Axioplan microscope.

\section{Immunofluorescence}

After deparaffinization, rehydration and antigen retrieval using EDTA buffer, $7 \mu \mathrm{m}$ thickness sections were blocked with 3\% BSA/0.1\% TritonX-100/ PBS for $30 \mathrm{~min}$ at room temperature to reduce background staining and 
incubated with primary antibodies for $2 \mathrm{~h}$ at room temperature. Fluorescencelabeled secondary antibodies were added for $1 \mathrm{~h}$ at room temperature. To confirm the specificity of antibodies, additional slides were incubated without the primary antibodies. No fluorescence staining was found in these sections. All sections were examined by using a Nikon Laser Scanning Confocal microscope (C1). We measured fluorescence intensity by defining the MEE remaining area manually, and calculated the mean pixel intensity per unit area of MEE remaining.

\section{Quantitative real time PCR}

For each time point, mid-regions of the midline from 2 pairs of palatal shelves were pooled, and 3-5 independent pools were analyzed. Total RNA was extracted with the use of RNeasy micro kit (Qiagen) and reverse transcribed with QuantiTect Rev. Transcription kit (Qiagen) according to the manufacturer's guidelines. SYBR-Green based real-time PCR was performed using SsoFast EvaGreen Supermix (Bio-Rad). Primers used in this study were obtained from PrimerBank (Spandidos et al., 2010). GAPDH expression levels were used as reference for normalization.

\section{Statistical analysis}

Statistical analyses were done using SPSS11.5 software. Results were evaluated by one-way analysis of variance (ANOVA) to compare the differences of means among multi-group data followed by a Tukey Kramer's post hoc test. Values are presented as means \pm SD. $P<0.05$ was considered to represent significant differences between groups.

\section{Acknowledgements}

Financial support was provided by research grant (RO1 DE16296) from National Institute of Dental and Craniofacial Research to CS.

\section{References}

BATSCHE, E., MUCHARDT, C., BEHRENS, J., HURST, H.C. and CREMISI, C. (1998). RB and c-Myc activate expression of the E-cadherin gene in epithelial cells through interaction with transcription factor AP-2. Mol Cell Biol 18: 3647-58.

CHEN, Y.G. (2009). Endocytic regulation of TGF-beta signaling. Cell Res 19: 58-70.

DAVE, N., GUAITA-ESTERUELAS, S., GUTARRA, S., FRIAS, A., BELTRAN, M., PEIRO, S. and DE HERREROS, A.G. (2011). Functional cooperation between Snail1 and twist in the regulation of ZEB1 expression during epithelial to mesenchymal transition. J Biol Chem 286: 12024-12032.

FERGUSON, M.W. (1988). Palate development. Development 103 Suppl: 41-60.

GREENE, R.M. and PISANO, M.M. (2010). Palate morphogenesis: Current understanding and future directions. Birth Defects Res C Embryo Today 90: 133-154.

GRIFFITH, C.M. and HAY, E.D. (1992). Epithelial-mesenchymal transformation during palatal fusion: carboxyfluorescein traces cells at light and electron microscopic levels. Development 116: 1087-1099.

HAMM-ALVAREZ, S.F. and SHEETZ, M.P. (1998). Microtubule-dependent vesicle transport: modulation of channel and transporter activity in liver and kidney. Physiol Rev 78: 1109-1129.

INGE, L.J., RAJASEKARAN, S.A., WOLLE, D., BARWE, S.P., RYAZANTSEV, S., EWING, C.M., ISAACS, W.B. and RAJASEKARAN, A.K. (2008). alpha-Catenin overrides Src-dependent activation of beta-catenin oncogenic signaling. $\mathrm{Mol}$ Cancer Ther 7: 1386-1397.

ISHIYAMA, N., LEE, S.H., LIU, S., LI, G.Y., SMITH, M.J., REICHARDT, L.F. and IKURA, M. (2010). Dynamic and static interactions between $\mathrm{p} 120$ catenin and E-cadherin regulate the stability of cell-cell adhesion. Cell 141: 117-128.

JALALI, A., ZHU, X., LIU, C. and NAWSHAD, A. (2012). Induction of palate epithelial mesenchymal transition by transforming growth factor beta3 signaling. Dev Growth Differ 54: 633-648.
JIN, J.Z. and DING, J. (2006). Analysis of cell migration, transdifferentiation and apoptosis during mouse secondary palate fusion. Development 133: 3341-3347.

JIN, M. and SNIDER, M.D. (1993). Role of microtubules in transferrin receptor transport from the cell surface to endosomes and the Golgi complex. J Biol Chem 268: 18390-18397.

JIN, Q., GAO, G. and MULDER, K.M. (2009). Requirement of a dynein light chain in TGFbeta/Smad3 signaling. J Cell Physiol 221: 707-715.

KAARTINEN, V., CUI, X.M., HEISTERKAMP, N., GROFFEN, J. and SHULER, C.F. (1997). Transforming growth factor-beta3 regulates transdifferentiation of medial edge epithelium during palatal fusion and associated degradation of the basement membrane. Dev Dyn 209: 255-260.

KITASE, Y. and SHULER, C.F. (2012). Multi-Layered hypertrophied MEE formation by microtubule disruption via GEF-H1/RhoA/ROCK signaling pathway. Dev Dyn 241: 1169-1182.

LASORELLA, A., NOSEDA, M., BEYNA, M., YOKOTA, Y. and IAVARONE, A. (2000). Id2 is a retinoblastoma protein target and mediates signalling by Myc oncoproteins. Nature 407: 592-598.

LIU, L., GUO, X., RAO, J.N., ZOU, T., XIAO, L., YU, T., TIMMONS, J.A., TURNER, D.J. and WANG, J.Y. (2009). Polyamines regulate E-cadherin transcription through c-Myc modulating intestinal epithelial barrier function. Am J Physiol Cell Physiol 296: C801-810.

MIYASHITA, Y. and OZAWA, M. (2007). Increased internalization of p120-uncoupled $\mathrm{E}$-cadherin and a requirement for a dileucine motif in the cytoplasmic domain for endocytosis of the protein. J Biol Chem 282: 11540-11548.

PEINADO, H., PORTILLO, F. and CANO, A. (2004). Transcriptional regulation of cadherins during development and carcinogenesis. Int J Dev Biol 48: 365-375.

PIETENPOL, J.A., HOLT, J.T., STEIN, R.W. and MOSES, H.L. (1990). Transforming growth factor beta 1 suppression of c-myc gene transcription: role in inhibition of keratinocyte proliferation. Proc Natl Acad Sci USA 87: 3758-3762.

PIROZZI, G., TIRINO, V., CAMERLINGO, R., FRANCO, R., LAROCCA, A., LIGUORI, E., MARTUCCI, N., PAINO, F., NORMANNO, N. and ROCCO, G. (2011). Epithelial to mesenchymal transition by TGFbeta-1 induction increases stemness characteristics in primary non small cell lung cancer cell line. PLoS One6: e21548.

RIMM, D.L., KOSLOV, E.R., KEBRIAEI, P., CIANCI, C.D. and MORROW, J.S. (1995). Alpha 1(E)-catenin is an actin-binding and -bundling protein mediating the attachment of F-actin to the membrane adhesion complex. Proc Natl Acad Sci USA 92: 8813-8817.

SCHMID, D.S., CF. (2002). Characterization of adherens junction components in the medial edge epithelium during palatogenesis. In The IADR/AADR/CADR 80th General Session, (ed. San Diego Convention Center).

SHIMOYAMA, Y., NAGAFUCHI, A., FUJITA, S., GOTOH, M., TAKEICHI, M., TSUKITA S. and HIROHASHI, S. (1992). Cadherin dysfunction in a human cancer cell line: possible involvement of loss of alpha-catenin expression in reduced cell-cell adhesiveness. Cancer Res 52: 5770-5774.

SHIRAKIHARA, T., SAITOH, M. and MIYAZONO, K. (2007). Differential regulation of epithelial and mesenchymal markers by deltaEF1 proteins in epithelial mesenchymal transition induced by TGF-beta. Mol Biol Cell 18: 3533-3544.

SHULER, C.F., HALPERN, D.E., GUO, Y. and SANK, A.C. (1992). Medial edge epithelium fate traced by cell lineage analysis during epithelial-mesenchymal transformation in vivo. Dev Biol 154: 318-330.

SPANDIDOS, A., WANG, X., WANG, H. and SEED, B. (2010). PrimerBank: a resource of human and mouse PCR primer pairs for gene expression detection and quantification. Nucleic Acids Res 38: D792-799.

SUN, D., VANDERBURG, C.R., ODIERNA, G.S. and HAY, E.D. (1998). TGFbeta3 promotes transformation of chicken palate medial edge epithelium to mesenchyme in vitro. Development 125: 95-105.

VAN ROY, F. and BERX, G. (2008). The cell-cell adhesion molecule E-cadherin. Cell Mol Life Sci 65: 3756-3788.

YU W, R.L., SVOBODA KK. (2009). Regulation of epithelial-mesenchymal transition in palatal fusion. Exp Biol Med 234: 483-491. 


\section{Further Related Reading, published previously in the Int. J. Dev. Biol.}

Programmed cell death is not a necessary prerequisite for fusion of the fetal mouse palate Sachiko Takahara, Toshiya Takigawa and Kohei Shiota Int. J. Dev. Biol. (2004) 48: 39-46

TGF-beta3 is required for the adhesion and intercalation of medial edge epithelial cells during palate fusion

Consuelo Tudela, Miguel-Angel Formoso, Tamara Martínez, Raquel Pérez, Marta Aparicio, Carmen Maestro, Aurora Del Río, Elena Martínez, Mark Ferguson and Concepción MartínezAlvarez

Int. J. Dev. Biol. (2002) 46: 333-336

R-twist gene expression during rat palatogenesis A Bloch-Zupan, N Hunter, A Manthey and J Gibbins Int. J. Dev. Biol. (2001) 45: 397-404

Bulging medial edge epithelial cells and palatal fusion

C Martínez-Alvarez, R Bonelli, C Tudela, A Gato, J Mena, S O'Kane and M W Ferguson Int. J. Dev. Biol. (2000) 44: 331-335

Rapid disappearance of the medial epithelial seam during palatal fusion occurs by multifocal breakdown that is preceded by expression of alpha smooth muscle actin in the epithelium

J R Gibbins, S Brent, M Srivastava, N Garibotto, Y M Tazawa, A Cameron and N Hunter Int. J. Dev. Biol. (2000) 44: 223-231

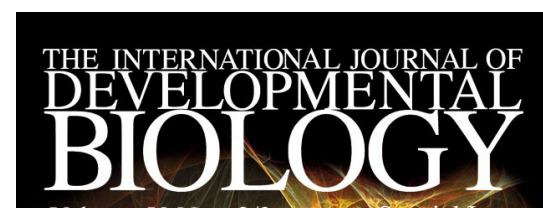

Volume 50 Nos. 2/3 s steeial Issue

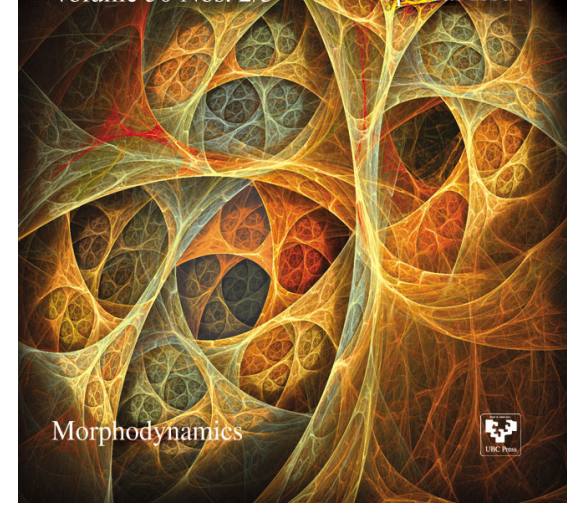

5 yr ISI Impact Factor $(2011)=2.959$
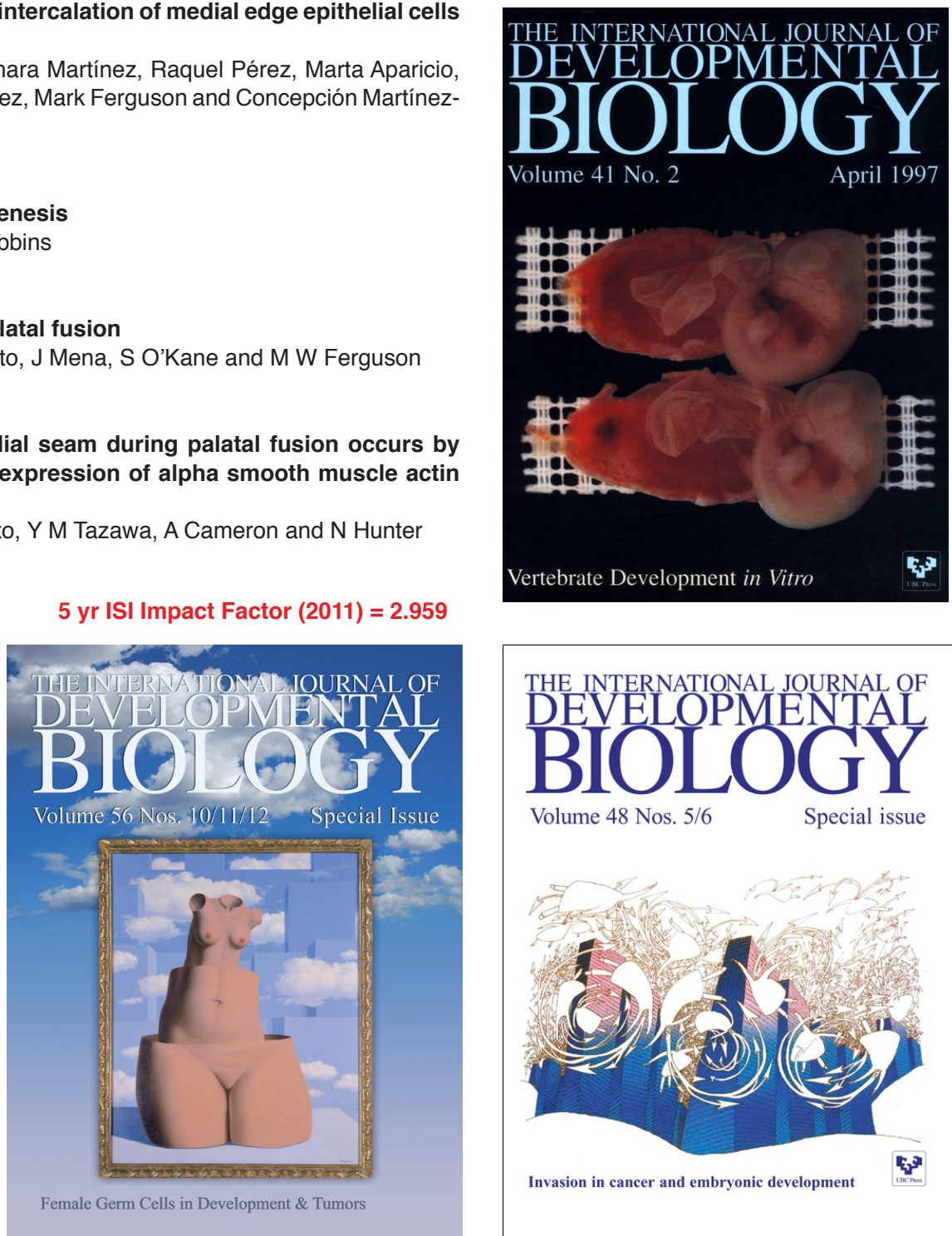

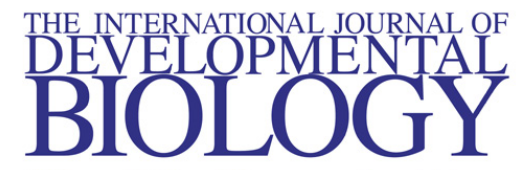

Volume 48 Nos. $5 / 6$
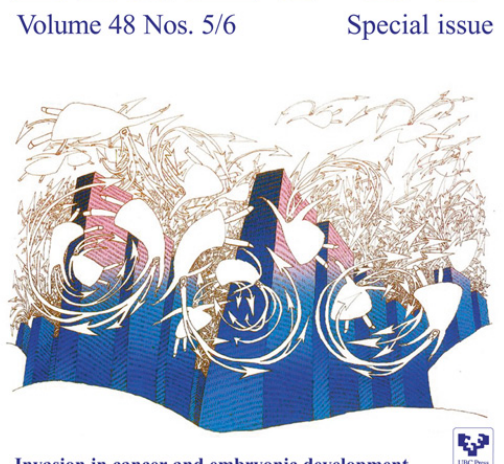

Invasion in cancer and embryonic development 